\title{
CARA IBU MENGATASI KESULITAN MAKAN PADA ANAK PRA SEKOLAH DI DESA PENYENGAT OLAK KABUPATEN MUARO JAMBI TAHUN 2015
}

\author{
Afridawaty $\mathbf{M J}^{\mathbf{1}}$
}

\begin{abstract}
Preschool children was the children who aged 3 to 5 years. The Groth and development of pre school children was influenced by the nutrition, activity, sleeping problem, dental health, prevention of an injury, and the parenting style.The nature of typical development influence children's eating patterns such as a child being too picky. Difficulty eating is when a child is unwilling or refuses to eat with the type or amount of physiologicalage appropriate. The pre school age children who have difficulty eating and can further lead to complication a and impaired child development, so we need a way to overcome adversity mother eating in children.The aimed of study was to determine the description how mothers cope with eating problem in pre school children in Penyengat Olak Village Muaro Jambi. This study was a quantitative descriptive. The sampling technique was simple random sampling wit 38 Persons were being the sample. The result showed from 38 respondent, 21 respondent $(55,2 \%)$ less well in dealing with eating problem in children. Difficulty eating in children ia an important issue for older people, if not treated early. It is expected the parents, especially the mother can detect the caused difficulty eatingin children so that treatment can be done quickly and accurately, and the parent were suggested applied the appropriate parenting style for the preschool children to maximize the aptitude.
\end{abstract}

Key word : Difficulty eating, mothers, pre school children

\section{PENDAHULUAN}

Anak prasekolah adalah anak yang berusia 3-5 tahun.Anak prasekolah mengalami pertumbuhan dan perkembangan biologis, psikososial, kognitif dan spiritual yang signifikan. Pertumbuhan dan perkembangan anak usia prasekolah dipengaruhi oleh nutrisi, masalah tidur, kesehatan gigi, pencegahan cedera serta cara orang tua dalam merawat anak yang sakit (Wong, 2008).

Usia pra sekolah, anak akan mengalami perkembangan psikis menjadi lebih mandiri, autonom, dapat berinteraksi dengan lingkungannya, serta lebih mengekspresikan emosinya. Bentuk luapan emosi yang terjadi adalah menangis atau menjerit saat anak tidak nyaman.Sifat perkembangan

${ }^{1}$ Akademi Keperawatan Jambi yang terbentuk ini dapat mempengaruhi pola makan anak.Hal tersebut menyebabkan anak terkadang pemilih, misalnya cenderung menyukai makanan ringan sehingga menjadi kenyang dan menolak makan saat waktu jam makan.(Soetjiningsih, 2009).

Nutrisi merupakanfaktor yang paling berpengaruh terhadap pertumbuhan dan perkembangan anak usia pra sekolah. Nutrisi pada anak usia pra sekolah harus mempunyai nilai gizi yang seimbang dan kalori yang mencukupi. Jika nutrisi tidak terpenuhi maka akan terjadi masalah pada pertumbuhan dan perkembangan, kebutuhan gizi yang tidak terpenuhi secara adekuat dapat menyebabkan gizi buruk pada anak usia pra sekolah.

Masalah makan pada anak berbeda dengan masalah makan pada 
orang dewasa.Masalah perilaku makan yang timbul dapat bervariasi dari memilih makan makanan tertentu, membatasi jumlah asupan makanan, makanan berlebihan, sampai terjadinya gangguan makan yang berdampak pada gangguan pertumbuhan dan perkembangan anak. Keluahan mengenai anak yang sulit makan menjadi masalah yang sering diungkapkan oleh orang tua ketika membawa anknya ke dokter. Beberapa masalah makan seperti rewel, muntah, terlalu pemilih, makan terlambat dan penolakan makan.

Kesulitan makan merupakan jika anak tidak mau atau menolak untuk makan atau mengalami kesulitan mengkonsumsi makanan atau minuman dengan jenis dan jumlah sesuai usia. (Sulistyoningsih, 2011).

Prevalensi kesulitan makan menurut klinik perkembangan anak dari affiliated program for childedren development di University George Town mengatakan 6 jenis kesulitan makan pada anak yaitu hanya mau makan makanan cair atau lumat : 27,3\%, kesulitan menghisap, mengunyah atau menelan : 24,1\%, kebiasaan makan yang aneh dan ganjil: $23,4 \%$, tidak menyukai variasi banyak makanan : $11,1 \%$. Keterlambatan makan sendiri : $8.0 \%$, mealing time tantrum 6,1\% (Judarwanto, 2011).

Angka kejadian masalah kesulitan makan dibeberapa Negara cukup tinggi. Penelitian The Gateshead Millenium Baby Study pada tahun 2009 di Inggris menyebutkan 20\% orang tua mengatakan anaknya mengalami masalah makan, dengan prevalensi tertinggi anak hanya mau makan makanan tertentu. Survei lain di Amerika lebih dari 20,5 \% ibu mengeluh karena memiliki anak yang susah makan sehingga mengakibatkan anak menjadi sangat kurus dan lemah dalam beraktifitas, dan ditemukan pada usia yang bervariasi terutama terjadi pada anak pra sekolah. (Wahono, 2010).

Penelitian di Indonesia yang dilakukan di Jakarta terhadap anak pra sekolah, didapatkan hasil prevalensi kesulitan makan sebesar 33,6\%, 44,5\% diantaranya menderita malnutrisi ringan sampai sedang dan $79,2 \%$ dari subjek penelitian telah mengalami kesulitan makan lebih dari 3 bulan (Judarwanto, 2011).

Penelitian Fitriani. dkk (2009), pada anak pra sekolah usia 3-5 tahun di perumahan Top Amin Mulya Jakabaring Palembang diperoleh 59,3\% anak mengalami kesulitan makan. Cara pemberian makan dengan dipaksa yaitu disuapi $(100 \%)$, suasana makan sambil bermain( $87 \%$ ), variasi makanan baik $(78 \%)$, waktu makan tidak teratur $(63,6 \%)$, frekuensi makan buruk $(78,1 \%)$, dan jenis makanan sesuai dengan usia anak (100\%).

Menurut WHO (2012), dalam Rohmasari 2013, diketahui bahwa $42 \%$ dari 15,7 juta kematian anak dibawah 5 tahun terjadi dinegara berkembang. Dari data tersebut sebanyak $84 \%$ kasus kekurangan gizi anak anak usia dibawah lima tahun (balita) terjadi di Asia dan Afrika. Sedangkan di Indonesia tahun 2012 terdapat sekitar $53 \%$ anak dibawah usia 5 tahun menderita gizi buruk disebabkan oleh kurangnya makanan untuk mencukupi kebutuhan gizi sehari-hari (Depkes, 2012).

Penelitian Sudibyo \& Mulyani (2009), kelompok usia terbanyak mengalami kesulitan makan adalah usia 1 sampai 5 tahun (58\%). Kesulitan makan sebanyak 50 orang dari 109 orang subjek $(45,9 \%)$.

Desa Penyengat Olak merupakan salah satu desa di kabupaten muaro jambi dengan jumlah balita terbanyak pada tahun 2011 sebanyak 296, tahun 2012 sebanyak 302 dan tahun 2013358 balita. Berdasarkan survey pendahuluan melalui wawancara 
kepada 10 orang ibu, 8 orang mengatakan tidak mengetahui cara untuk mengatasi kesulitan makan pada balita, ibu tidak memberikan anak makanan dengan bentuk yang bervariasi, ibu tidak menggunakan peralatan makan yang menarik, ibu hanya memberikan makanan yang sama setiap harinya dan tidak memvariasikan bentuk dan rasa makanan. Berdasarkan hal tersebut diatas maka peneliti tertarik untuk melakukan penelitian mengenai "Cara ibu mengatasi kesulitan makan pada anak pra sekolah di Desa Penyengat olak Kabupaten Muaro Jambi “

\section{METODOLOGI PENELITIAN}

Penelitian ini merupakan penelitian Deskriptif Kuantitatif yang bertujuan untuk mengetahui cara ibu mengatasi kesulitan makan pada anak pra sekolah di Desa Penyengat Olak Kabupaten Muaro Jambi Tahun 2015. Populasi dalam penelitian ini adalah seluruh ibu yang memiliki anak pra sekolah dengan jumlah sebanyak 311 orang. Pengambilan sampel dengan simple random sampling sesuai dengan kriteria inklusi ibu yang memilki anak usia 3-5 tahun dan bersedia menjadi responden dengan jumlah 38 orang. Penelitian ini dilakukan pada tanggal 26 Juni sampai 26 Juli 2014.

Analisa data yang digunakan yaitu analisa univariat untuk melihat distribusi frekuensi.

\section{HASILPENELITIAN}

Penelitian ini telah dilakukan tanggal 12-15 september 2014.

\section{Tabel 1 : Distribusi Frekuensi} Karakteristik Responden

\begin{tabular}{|c|c|c|c|}
\hline No & $\begin{array}{c}\text { Karakteritik } \\
\text { Responden }\end{array}$ & $\mathrm{n}$ & $\%$ \\
\hline 1 & Usia Anak & & \\
\hline & $3-4 t$ & 32 & 84,2 \\
\hline & 5 tahun & 6 & 15,8 \\
\hline 2 & $\begin{array}{l}\text { Usia Ibu } \\
20-35 \text { tahun }\end{array}$ & 27 & 71.1 \\
\hline
\end{tabular}

36-50 tahun $11 \quad 28.9$

3 Pendidikan

$\begin{array}{lll}\text { SD } & 19 & 50\end{array}$

$\begin{array}{lll}\text { SMP } & 10 & 26.3\end{array}$

$\begin{array}{lll}\text { SMU } & 6 & 15.8\end{array}$

$\begin{array}{lll}\text { PT } & 3 & 7.9\end{array}$

Mayoritas responden memiliki anak usia 3-4 tahun (84,3\%), dan mayoritas ibu usia 20-35 tahun $(71,7 \%)$, pendidikan responden SD (50\%).

Tabel 2 :Distribusi Frekuensi Cara

Ibu Mengatasi Kesulitan Makan

\begin{tabular}{cccc}
\hline No & $\begin{array}{c}\text { Cara Ibu mengatasi } \\
\text { kesulitan makan }\end{array}$ & $\mathrm{n}$ & $\%$ \\
\hline 1 & Baik & 17 & 44.8 \\
\hline 2 & Kurang baik & 21 & 55.2 \\
\hline
\end{tabular}

Hasil penelitian pada tabel 2 menunjukkan bahwa cara ibu mengatasi kesulitan makan pada anak dengan kategori kurang baik yaitu 21 $(55,2 \%)$.

\section{PEMBAHASAN \\ Data Demografi}

Hasil analisa univariat menunjukkan usia anak (3-4) tahun sebesar $(84.2 \%)$. Dengan usia terendah 3 tahun dan tertinggi 5 tahun. Anak pra sekolah adalah anak usia 3 sampai 5 tahun. Pada masa ini, terjadi pertumbuhan biologis, psikososial, kognitif dan spiritual yang begiru signifikan.

Sebagian besar usia ibu adalah usia dewasa awal yang mana dalam perkembangan psikososialnya seseorang siap dan ingin untuk menyatukan identitasnya dengan orang lain serta membuka diri terhadap dunia masyarakat luas untuk memberikan sumbangannya yang berarti.

Pendidikan responden terbanyak adalah SD, Pendidikan mempengaruhi pemahaman ibu terhadap anak usia pra sekolah sehingga mempengaruhi kesiapan mereka dalam menjalankan pengasuhan. 
Kesulitan makan banyak terjadi pada usia pra sekolah. Berdasarkan beberapa penelitian menunjukkan bahwa kesulitan makan banyak terjadi pada anak pra sekolah. Penelitian ini sesuai dengan Beautris (2007), terdapat $24 \%$ responden di New Zealand yang mengatakan anaknya mengalami kesulitan makan di usia 2 tahun dan $18 \%$ diantaranya berlanjut hingga usia 4 tahun.

Menurut peneliti, usia pra sekolah merupakan usia dimana anak bisa memilih makanan yang disukainya, seringkali anak jadi beralasan tidak mau makan karena masih kenyang akibat sering ajajn atau mengkonsumsi makanan ringan. (Retnosari, 2009).

Cara ibu mengatasi kesulitan makan pada anak pra sekolah dipengaruhi oleh usia dan pendidikan . Dilihat dari usia responden mayoritas berusia 20-35 tahun dan dilihat dari tingkat pendidikan sebagaian besar SD. Pengetahuan ibu dalam merawat anak sangat penting, salah satunya dalam mengatasi kesulitan makan anak. (Notoadmodjo, 2010).

\section{Cara ibu mengatasi kesulitan makan pada anak pra sekolah}

Berdasarkan hasil penelitian didapatkan dari 38 responden sebagian besar cara mengatasi kesulitan makan kurang baik 21 responden $(55,2 \%)$. Penelitian ini sesuai dengan yessi (2010) bahwa upaya kesulitan makan pada anak dari 28 responden sebanyak 23 orang memilki upaya yang kurang baik dalam mengatasi kesulitan makan. pada anak pra sekolah.

Menurut Widodo (2009), cara pemberian makan pada anak yang tidak tepat dapat menjadikan kesulitan makan pada anak, meliputi memberikan makan dengan marahmarah atau kasar, suka memaksa anak untuk menghabiskan makanan dengan cepat, memberikan makan terlalu banyak, dan waktu yang tidak tepat, sehingga membuat acara makan pada anak menjadikan hal menyedihkan pada anak.

Untuk menciptakan suasana yang mendorong anak agar makan dengan baik adalah dengan menciptakan lingkungan makan yang bersih, hindari dari kebisingan, panas dan gangguan luar lainnya. Mendengarkan alunan musik dengan irama santai, dan makan secara bersam-sama akan meningkatkan nafsu makan pada anak (Sulistyoningsih, 2010).

Cara mengatasi kesulitan makan yang salah sering memperbesar kesulitan makan anak karena dapat mengurangi selera makan. Tindakan perilaku yang perlu diperhatikan orang tua atau pengasuh anak yaitu jangan terlalu memaksa cara amakn pada anak, jangan member ancaman jika makanannya tidak dihabiskan, jangan memaksa anak membuka mulut, dan jangan memaksa porsi makan harus habis, jangan melarang anak memilih menu makan yang diinginkan, dan jangan menghukum anak jika anak tidak mau makan (Judarwanto, 2011).

Menurut asumsi peneliti, anak yang mengalami kesulitan makan disebabkan oleh tidak terpenuhinya keinginan terhadap suatu makanan, baik dari segi warna makanan, tekstur makanan maupun bau makanan, tetapi ada juga anak yang tidak mau makan jika orang tuanya tidak menyediakan sesuatu barang atau maianan yang dapat membuat anak mau makan.

\section{SIMPULAN}

Berdasarkanhasilpenelitiandanura ianpembahasanpadababsebelumnyadap atdisimpulkan:

1. Karakteristik responden

a. Berdasarkan usia anak, sebagian besar berusia 3-4 tahun sebanyak 32 responden $(84,2 \%)$. 
b. Berdasarkan usia ibu, sebagian besar berusia 20-35 tahun sebanyak 27 responden $(71,1 \%)$.

c. Berdasarkan tingkat pendidikan, sebagian besar tingkat pendidikan responden adalah SD sebanyak 19 responden (50\%).

2. Cara Ibu mengatasi kesulitan makan pada anak pra sekolah diketahui sebagian besar kurang baik sebanyak 21 responden $(55,2 \%)$.

\section{Saran}

1. Bagi Pelayanan Keperawatan

Diharapkan agar dapat lebih meningkatkan pelayanan, terutama dalam pemberian informasi tentang kesulitan makan pada anak pra sekolah.

2. BagiInstitusiKeperawatan

Meningkatkan pemahaman pada peserta didik, bahwa dalam mengatasi kesulitan makan pada anak pra sekolah perlu memberikan edukasi dalam cara mengatasi kesulitan makan pada anak.

3. BagiPenelitianselanjutnya

Disarankan untuk peneliti selanjutnya untuk dapat melakukan penelitian mengenai faktor-faktor yang berhubungan dengan kesulitan makan pada anak.

\section{DAFTAR PUSTAKA}

Adiningsih (2010). Waspadai Gizi Balita Anda : Tips Mengatasi Anak Sulit Makan, Sulit Makan Sayur dan Susu, Jakarta : PT Elex Media Komputindo

Aisyah (2011). Perilaku ibu terhadap anak dengan masalah sulit makan pada Puskesmas Ponorogo diperoleh tanggal 27 Maret 2014 dari http//: www.akbidharapanmulya.ac.id

Depkes RI (2012), Kebutuhan Gizi Balita, Dirjen PPM \&PLP

Fitriani, Fatmalina, Rini ,M (2009), Gambaran penyebab kesulitan makan pada anak pra sekolah usia 3-5 tahun di Perumahan
Top Amin Mulya Jakabaring Palembang. Diperoleh tanggal 3 jnuari 2014 dari http : eprint. Unsri.ac.id/58/3 abstrak.pdf

Friedman M.M, Bowden V.R (2003) Family Nursing: Research Theory \&Practice New Jersey : Person Education, Inc

Judarwanto, (2010).Sulit Makan dan Gangguan Perilaku Diperoleh tanggal 4 januari 2015 dari http://klinikanakonline.com

Judarwanto, W (2011). Mengatasi Kesulitan Makan pada Anak Jakarta : Puspa Swara.

Karaki, Karlie, bellafily, dkk (2016) Hubungan Pola Asuh ibu dengan perilaku sulit makan pada anakusia pra sekolah (3-5) tahun di TK Desa Paleon Kec. Minahasa Selatan. Jurnal Keperawatan Vol 4 (2) 2016 http :// ejournal. Unstrat.ac.id diunduh pada tanggal 24 Maret 2014

Marni (2013), Gizi dalam kesehatan Reproduksi Yogyakarta : Gramedia.

Mascola, Bryson \& Agra (2010), Picky Eating during childhood : a longitudinal study age to 11 years. Eating Behaviours, 11, 253-257

Notoadmodjo (2010), Pendidikan Perilaku Kesehatan, Jakarta: PT Gramedia.

Ostberg, M \& Hagelin (2010). Feeding anad Sleping problems in infancy a follow up at early school age. Blackwell Publishing Ltd, 37, 1125

Retno sari, S (2009). Mengatasi Anak Sulit Makan, Jakarta: PT gramedia.

Rohmasari, A (2013) Faktor-faktor yang mempengaruhi sulit makan pada Balita diperoleh tanggal 27 Maret 2014 dari http : www.lib.umpo.ac.id/gdl/downloa d.php?-id 532 
Sudibyo\& Mulyani (2009) Kesulitan Makan pada Pasien = Survey di Unit Pediatric Rawat Jalan. Jurnal Sari Pediatri

Soetjiningsih (2004), Tumbuh Kembang Anak, Bali EGC

Wong, D. 1, Marylin L.w, (2008) Buku Ajar Keperawatan Pediatric, Jakarta : EGC 